\title{
Democracia Participativa y Políticas Sociales en el Gobierno de Hugo Chávez Frías
}

\author{
López Maya, Margarita* \\ * Licenciada en Historia y Doctora en Ciencias Sociales de la Universidad Central de \\ Venezuela. Profesora titular del Centro de Estudios del Desarrollo (Cendes) de la misma \\ UCV. Directora de la Revista Venezolana de Economía y Ciencias Sociales. E-mail: \\ malopez@reacciun.ve.
}

\section{Resumen}

En este artículo se analiza la acción gubernamental del presidente Hugo Chávez Frías, centrando el foco en la dimensión social de esa acción. Se argumenta sobre el carácter de "democracia sustantiva" que propone el proyecto político "bolivariano" elaborado en los años 90 por fuerzas sociales y políticas de izquierda lideradas por Chávez y su materialización en la Constitución de 1999 y en las “Líneas Generales del Desarrollo Económico y Social de la Nación, 2001-2007". Se exponen los ejes del "equilibrio social" que orientan la acción estatal actual y entre otras políticas sociales medulares, se examinan algunas "misiones" que se han venido desarrollando desde que se superó el paro-sabotaje" petrolero de diciembre 2002 -febrero 2003, proporcionando cifras principalmente oficiales, que son hasta ahora las disponibles.

Palabras clave: Democracia participativa, proyecto bolivariano, gobiernos de izquierda, políticas sociales.

\section{Participant Democracy and Social Policies in Hugo Chávez Government}

\begin{abstract}
In this article we analyze the governmental action of President Hugo Chavez, centering our attention on the social dimension of that action. The character of "substantive democracy" which is proposed in the bolivarian political project, and which was developed during the 1990s by leftist social and political forces under the leadership of Chavez, is discussed, as well as its solidification in the 1999 Constitution under the title General lines of economic and social development of the nation, 2001-2003. The axis of social equilibrium which orient present state action, as well as other medullar social policies are
\end{abstract}


discussed. The missions that have been developed since the recovery from the oil sabotage-stoppage from December 2002 to February 2003, are examined, and the official statistics available presently are offered.

Key words: Participative democracy, bolivarian projects, leftist governments, social policies.

Recibido: 04-10-15. Aceptado: 04-11-16

\section{I ntroducción}

Desde 1999, el Estado venezolano ha venido desarrollando un proyecto político de naturaleza "alternativa" a los predominantes en América Latina. Este proyecto, de "democracia participativa y protagónica", contrasta con las democracias representativas características de la región. Se identifica como el proyecto “bolivariano", por provenir del movimiento sociopolítico inspirado por Simón Bolívar, que lidera Hugo Chávez Frías, actual Presidente de Venezuela. Recientemente, ha sido reconocido por algunos estudiosos como un proyecto "contrahegemónico", por oponerse en su concepción y prácticas sociopolíticas a proyectos cuyos lineamientos generales se orientan por la doctrina neoliberal, que es actualmente hegemónica en el sistema capitalista mundial (Lander, 2004). El proyecto bolivariano recibió su primera materialización institucional con la Constitución de la República Bolivariana de Venezuela, elaborada en la Asamblea Constituyente de 1999 y aprobada por referendo popular en diciembre de ese mismo año. En 2001 fueron aprobadas las “Líneas Generales del Plan de Desarrollo Económico y Social de la Nación, 2001-2007" (LGPDESN), con lo cual el Estado se dotó de un primer instrumento normativo que orientaría su acción de acuerdo a las directrices constitucionales. Desde entonces un conjunto de normas, leyes y prácticas sociopolíticas han ido expandiendo el ámbito de desarrollo de este proyecto político.

El proyecto de democracia participativa en su dimensión social constituye una novedosa y creativa manera en América Latina de afrontar los graves problemas de exclusión e injusticia social que confrontan estas sociedades. Por ir esta propuesta a contracorriente del pensamiento hegemónico mundial, ha sido visto con desconfianza y franca aversión, tanto entre ciertos actores sociopolíticos y factores de poder en la sociedad venezolana, como también por parte de actores hegemónicos del sistema capitalista mundial. I gualmente, despierta mucha desconfianza entre grupos y actores políticos de orientación ideológica de izquierda, entre otras razones, por originarse de fuentes distintas a las tradicionales del marxismo. Los resultados de la exploración hecha sobre esta dimensión 
del proyecto, que aquí se presentan, buscan una mayor comprensión de sus bases conceptuales y de su práctica, como contribución para el debate sobre los fundamentos de proyectos políticos progresistas o de izquierda en el siglo XXI.

Este artículo se organiza en 3 partes. En la primera, se presenta el contexto sociopolítico venezolano de los años 80 y 90, que permite explicar el surgimiento en esta sociedad de la propuesta de democracia "participativa" por parte de actores políticos emergentes de izquierda. En la segunda parte, se revisa el concepto de "democracia participativa y protagónica" de la Constitución de 1999 y de las Ĺneas Generales del Plan de Desarrollo Económico y Social de la Nación 2001-2007 (LGPDESN), extrayendo la concepción de lo social presentado por estos textos. En la tercera parte, se exponen los ejes de la política social del gobierno de Chávez y se revisan los objetivos de algunas políticas hasta ahora implementadas. Se cierra con unas conclusiones.

\section{La democracia en la experiencia venezolana}

La experiencia venezolana con la democracia como régimen político y práctica social contrasta con otras sociedades latinoamericanas, de modo notorio con las del cono sur, que cayeron en dictaduras en los años 60, 70 y 80, y recuperaron una democracia restringida lustros después. Experiencias como la de Argentina y Chile fueron de gran importancia en el debate teórico sobre el tema de la democracia en la región, pues marcaron las orientaciones generales de la academia latinoamericana y estadounidense sobre América Latina, así como también la práctica de actores sociales y políticos de la región. El contraste de estas experiencias con la venezolana ha contribuido a las dudas y resistencias que ha despertado la "democracia participativa y protagónica" que se ensaya en Venezuela, y la dificultad para algunos de ubicarla como una propuesta situada en la “izquierda” política de América Latina.

Según bibliografía relevante sobre esta materia, los años de "transición democrática", característicos de muchas sociedades de la región en los años 80 y 90, fueron posibles gracias a una negociación entre factores de poder autoritarios y actores sociopolíticos democráticos, alrededor del respeto a una democracia formal, "mínima" o procedimentalı1. Las democracias prevalecientes con anterioridad, como la chilena, brasileña o argentina, que aspiraban a equidad y justicia social, habrían colapsado -se diagnosticó- al agotarse el modelo de sustitución de importaciones, y al hacerse las demandas crecientes de la población, insostenibles financieramente para el Estado. Según esta línea argumentativa, el exceso de demandas provocó el cierre del ciclo de los nacional-populismos en América Latina y abrió el de las dictaduras. Las movilizaciones, las exageradas exigencias a la 
democracia, señaló entre otros Lechner (1994), estuvieron entre los aspectos que hicieron al péndulo volver al lugar de las dictaduras feroces, de los regímenes autoritarios, característicos del pasado latinoamericano. Los latinoamericanos, sobre todo en el cono sur, padecieron con ello represión masiva, torturas, desapariciones y toda suerte de violaciones a sus derechos humanos.

Este diagnóstico trajo como consecuencia la valoración de dos aspectos de cultura política que antes eran menospreciados en la región, especialmente por parte de la izquierda: uno, la valoración de la democracia procedimental o "mínima", como manera de garantizar un orden político de respeto a los derechos civiles y humanos de la población. Se hizo muy fuerte la convicción de que a partir de una democracia procedimental, podría poco a poco irse ensanchando los espacios democráticos de la sociedad, para alcanzar mayores niveles de justicia y equidad social. La obtención de este tipo de democracia abrió la esperanza de un mundo mejor para las grandes mayorías de la región. La izquierda política, sobre todo en el cono sur, que antes consideraba, debido al legado leninista, a la democracia representativa como "burguesa" y despreciable, se concilió con lo procedimental, aprendió a valorarla (Roberts, 1998: 11-13).

El otro aspecto que cambió en la cultura política del cono sur, según sostuvieron científicos sociales como Manin (1992) o Novarro (1997), fue la relación de la población con el Estado. Se produjo entre los sectores populares, un extrañamiento y una desconfianza hacia el Estado, valorándose positivamente su retracción de la regulación en diversos ámbitos de la vida social. La cultura política popular se volvió proclive a la privatización (Novarro, 1997: 118-119). La experiencia de un Estado enemigo, torturador y violador de derechos básicos, vivida dramáticamente por los sectores populares durante las dictaduras trajo esta consecuencia. Se legitimó la idea de que mientras menos Estado, mejor.

Estos cambios en la cultura política no fueron vividos de la misma forma por la sociedad venezolana. En este caso, nunca se produjo un colapso de la democracia representativa por excesivas demandas de la sociedad al Estado. Lo que sucedió fue un deterioro de la democracia representativa y sus actores hegemónicos, al mostrarse éstos incapaces de remontar la crisis de la deuda de los primeros años 80, al negarse a aprobar reformas estatales de profundización de la democracia, exigidas crecientemente por diversos sectores sociales y políticos, y al implementar, a pesar del expreso rechazo del electorado, planes de ajuste y reformas económicas de orientación neoliberal. Por ello, a diferencia de países con un pasado reciente de dictadura, la valoración de la democracia "formal", o procedimental, no goza de significativa estima en Venezuela. Para los venezolanos, su 
experiencia más bien les indica que con ella no se alcanza progresivamente una sociedad más equitativa e incluyente. Al contrario, ante las dificultades, lo formal de la democracia facilita y puede llegar a legitimar la exclusión económica, social y política de porciones significativas de la población.

Esta diferencia en la experiencia política reciente, contribuye a explicar, tanto la búsqueda temprana en Venezuela -en relación a otros países de la región- de una opción más sustantiva de democracia que la procedimental, como también, paradójicamente, por qué permanecen entre los actores sociopolíticos venezolanos, incluyendo partidos y organizaciones políticas de izquierda, rasgos autoritarios que reflejan poca estima por lo procedimental de la democracia. Ambos rasgos han convivido en esta cultura política como resultado de su particular experiencia con la democracia.

En los primeros años de gobierno de Chávez, en múltiples ocasiones observamos como éste y los partidos que lo apoyan, algunos pertenecientes u originados de la izquierda ideológica, recurrieron a procedimientos si bien legales, reñidos con una práctica democrática transparente $\underline{2}$. Un caso fue el de la designación de los miembros "transitorios" del Tribunal Supremo de Justicia por parte de la "Comisión Legislativa Nacional", mejor conocida como el "Congresillo" en 2000. El Congresillo fue un órgano deliberativo provisional designado por la Asamblea Nacional Constituyente, luego de la aprobación de la Constitución de 1999, para resolver problemas político-administrativos en el lapso contemplado desde la disolución de la Constituyente hasta la elección de los diputados de la nueva Asamblea Nacional.

Era una institución inadecuada y poco legítima para nombramientos urgidos de una sólida legitimidad como el de los miembros de ese Tribunal $\underline{3}$. También puede señalarse entre otros casos, la forma como fueron aprobadas 49 leyes en noviembre de 2002, algunas medulares del proyecto político bolivariano, como la Ley de Tierra y la Ley de Hidrocarburos, mediante facultades extraordinarias conferidas por la Asamblea Nacional al Ejecutivo a través de la llamada "ley Habilitante". Este procedimiento, reñido con el concepto "participativo" de la Constitución, permitió que estas leyes fueran aprobadas sin discusión parlamentaria ni negociación entre sectores afectados y el gobierno.

Estos y otros casos reflejaban la poca importancia que parecían darle los actores hegemónicos a utilizar procedimientos transparentes, que dieran solvencia democrática al marco jurídico-legal que comenzaba a construirse. Por el lado de las fuerzas de la oposición, basta observar la recurrencia permanente a estrategias de naturaleza insurreccional y violenta para derrocar al Presidente desde 2001: golpe de Estado en abril 
2002, paro-sabotaje petrolero, llamados a desobediencia tributaria, operaciones con paramilitares, operaciones de cierres violentos y masivos de vías públicas ("operación guarimba"), entre otras manifestaciones de la oposición4. En la sociedad venezolana se ha manifestado en estos años, tolerancia y hasta aceptación de tendencias autoritarias de ambos bandos políticos. Después del golpe de Estado, sin embargo, la sociedad como un todo, y algunos actores de gobierno y oposición, han venido reflejando en sus conductas un cambio que refleja una valorización creciente de la democracia procedimental, al encontrarla, dentro de la alta conflictividad vivida, una manera efectiva de adquirir respaldo internacional para sus proyectos políticos, así como una forma más segura de resguardar los derechos humanos, civiles y políticos de la población.

Por otra parte, las permanentes movilizaciones callejeras de los últimos 20 años señalan, a diferencia de lo que se ha sostenido para sectores populares de sociedades del cono sur, que sectores populares en Venezuela mantienen su exigencia de una democracia que cumpla con las aspiraciones de educación, salud y justicia social (López Maya y Lander, 2000). El repudio a la intervención del Estado es en Venezuela muy menor al caso de su rechazo en otras sociedades, toda vez que los venezolanos no han experimentado la represión masiva y continuada que sucedió en las experiencias autoritarias en otras partes de América Latina. La condición petrolera del Estado venezolano también contribuye a fortalecer la percepción popular de su necesaria o conveniente injerencia en economía y otros aspectos que corrijan la exclusión e injusticia sociales. Se ha señalado, sin embargo, que en los años 90 se produjo una diferenciación en la cultura política de los sectores populares con relación a las clases medias y altas. Estas últimas fueron convenciéndose de las bondades de la retracción del Estado en las distintas actividades socioeconómicas, en contraste con los sectores populares que siguieron valorando la acción del Estado como garantía para el desarrollo de sus derechos (Roberts, 2003). Un ingrediente que contribuye a la severa polarización política que hoy presenta la sociedad.

\section{La concepción de "democracia participativa y protag ónica"}

El proyecto bolivariano plasmado en la Constitución de 1999, difiere conceptualmente de otros gobiernos de la región en su enfoque sobre la democracia y por tanto en su manera de ver y manejar las diversas dimensiones de la vida del hombre en sociedad. El gobierno de Chávez y las fuerzas políticas que lo apoyan ensayan desde 1999 una "democracia participativa y protagónica". Dice el preámbulo de la Constitución: El pueblo de Venezuela, en ejercicio de sus poderes creadores (....) con el fin supremo de refundar la República para establecer una sociedad democrática, participativa y protagónica, multiétnica y pluricultural en un Estado de justicia federal y descentralizado (...) decreta la siguiente 


\section{Constitución.}

Y en sus artículos 2 y 6 :

Venezuela se constituye en un Estado democrático y social de Derecho y de Justicia, que propugna como valores superiores de su ordenamiento jurídico y de su actuación, la vida, la libertad, la justicia, la igualdad, la solidaridad, la democracia, la responsabilidad social $y$, en general, la preeminencia de los derechos humanos, la ética y el pluralismo político.

El gobierno de la República Bolivariana de Venezuela y de las entidades políticas que la componen es y será siempre democrático, participativo, electivo, descentralizado, alternativo, responsable, pluralista y de mandatos revocables.

La democracia participativa se entiende como una democracia que implica el autodesarrollo y la autogestión de los ciudadanos en todos los aspectos de la vida social:

La participación del pueblo en la formación, ejecución y control de la gestión pública es el medio necesario para lograr el protagonismo que garantice su completo desarrollo, tanto individual como colectivo. Es obligación del Estado y deber de la sociedad facilitar la generación de las condiciones más favorables para su práctica (art. 62).

El "protagonismo" de los ciudadanos es complementado por un rol activo del Estado, que de acuerdo con las LGPDESN, significa "acompañar" a los ciudadanos en la solución de los diversos y graves problemas que los aquejan. Se considera, según esta matriz conceptual, que la acción en pro de una sociedad mejor es responsabilidad tanto del Estado como de los ciudadanos y las familias (LGPDESN, 2001: 83 y ss.). Los problemas a superar se diagnostican como "estructurales" y se expresan en lo social en exclusión, injusticia y desigualdad de la mayoría de sus miembros. Dos sujetos políticos entonces son cruciales desde la visión del proyecto bolivariano y de las LGPDESN: el Estado en todos sus niveles administrativos y ramas, como el creador de condiciones que harán posible el "empoderamiento" de los ciudadanos, y éstos, que a través de su organización y participación, vayan transformándose en sujetos políticos con valores como la solidaridad, el respeto a los procedimientos democráticos y la corresponsabilidad.

Lo social en el proyecto bolivariano guarda afinidad con las premisas de la democracia participativa, llamada también "sustantiva", debatidas tanto en el pensamiento liberal democrático (desde Rousseau) como en el socialismo democrático (con Poulantzas). En el debate teórico sobre las bondades de este tipo de democracias, que tuvo lugar en las últimas décadas del siglo $X X$, se sostiene que no es suficiente que haya instituciones 
democráticas representativas a nivel nacional para que haya democracia. Para alcanzar la máxima socialización o entrenamiento para la democracia es necesario que ésta se extienda a otras esferas de la vida, permitiendo el desarrollo de actitudes individuales y cualidades psicológicas.

La participación permite educar para la democracia en el más amplio sentido de la palabra (Pateman en Vergara, 1998: 155-179). Partiendo de planteamientos formulados por J.J. Rousseau y James Stuart Mill, Carole Pateman, una de las teóricas más leídas en los años 70, sostuvo que la democracia participativa favorece el desarrollo humano, aumenta la eficacia política, reduce la alienación a los poderes centrales, estimula la preocupación por los problemas colectivos y contribuye a formar una ciudadanía activa, informada y experimentada en los asuntos públicos (Pateman en Vergara, 1998: 155179). Otro teórico de la corriente liberal (Macpherson en Vergara 1998), señaló que para que exista un modelo participativo hace falta que el ciudadano común deje de comportarse como simple consumidor de bienes y empiece a pensar y actuar como personas que ejercen sus propias capacidades y disfrutan con su ejercicio, dicho autor también sostuvo la necesidad de disminuir las desigualdades sociales y económicas, como condición para alcanzar sociedades participativas. Estas ideas influencian el enfoque que sobre la democracia sostienen los actores políticos actualmente hegemónicos en Venezuela.

Los partidos y organizaciones que tienen hoy el predominio político en la sociedad, venían sosteniendo desde los años 90, que la democracia es sobre todo acceso a recursos productivos, a servicios claves como educación y salud, y a toma de decisiones de los ciudadanos en los diversos ámbitos de la vida en sociedad. En 1997, uno de los fundadores del Movimiento Quinta República (MVR), el filósofo José Rafael Núñez Tenorio, lo resumió durante una entrevista: “El corazón de la democracia es la participación protagónica de la gente del pueblo en las decisiones que les afectan. Ahora sólo tienen el voto, pero nosotros vamos a abrir todos los canales para que el pueblo sea protagónico [...] estamos empeñados en hacer un programa que yo he llamado: Pueblo haz con nosotros el programa de Chávez, que comenzará con foros y seminarios desde la base (Núñez Tenorio, entrevista, agosto, 1997). Y ese mismo año, en entrevista a Aristóbulo Istúriz, del partido Patria Para Todos (PPT), actual ministro de Educación y Deportes, éste afirmaba que “... no tiene ningún sentido que tengamos toda la riqueza del mundo si no hay la posibilidad de acceder al disfrute de esas riquezas. Por eso, el tema de la democracia debe afincarse en el acceso a la riqueza. Las libertades públicas y el derecho al voto, están muy bien, pero no es suficiente. La estabilidad democrática en Venezuela tuvo que ver con el acceso a educación, con salud, aunque hay gente que no está de 
acuerdo con eso. Yo sí creo que eso fue importante" (Istúriz, entrevista, agosto, 1997).

En las LGPDESN se plantea una visión holística ante los problemas de la sociedad, es decir, éstos deben verse, analizarse y atacarse como un todo, a través de una serie de estrategias envolventes que se definen en 5 campos interrelacionados entre sí, uno de los cuales es el social. Las LGPDESN Ilaman a estos campos, los 5 "equilibrios" necesarios para salir de la crisis estructural (2001: 5-6). Esos equilibrios serían además del social: el económico, el político, el territorial y el internacional. Según las LGPDESN, no existe una política económica divorciada de una política social, ambas forman parte de un todo y una amerita de la otra. Se afirma en este texto, que si bien la finalidad de las políticas económicas es la reactivación del aparato productivo, para que se produzca mayor ingreso y distribución de la riqueza, lo que es también un logro social, el "equilibrio" económico no se alcanza si no se producen condiciones de justicia social. "Lo econ ómico afecta lo social y a la inversa, y tal dinámica se da entre los cinco equilibrios debido a sus múltiples reacciones" (LGPDESN, 2001: 6). Las LGPDESN son muy contundentes al rechazar las políticas focalizadas y de "combate a la pobreza", que el Estado venía implementando en los últimos lustros, bajo una matriz conceptual afín a las orientaciones neoliberales (LGPDESN, 2001: 93).

\section{Ejes del equilibrio social y algunas políticas medulares}

Según las LGPDESN que venimos analizando, el objetivo de la política social será corregir las "enormes distorsiones sociales" que se expresan en la exclusión e injusticia social, conjuntamente con potenciar el pleno desarrollo del ciudadano en los aspectos relacionados con la democracia. Para ello deben cambiarse las condiciones materiales y sociales de vida de las mayorías venezolanas, quienes hasta la fecha han estado separados del acceso equitativo a la riqueza y al bienestar. También es imperativo construir una nueva condición de ciudadanía, basada en el pleno reconocimiento de los derechos y el ejercicio de los mismos (LGPDESN, 2001: 91-92).

Para acometer estos propósitos se establecen tres ejes de acción: uno, centrado en superar la desigual distribución de la riqueza y del ingreso; otro, que busca alcanzar la equidad en el acceso y ejercicio de los derechos humanos. Y una tercera, que es lograr el pleno desarrollo del ciudadano. Por esto último, se entiende lograr una persona capaz de organizarse, asociarse, con identidad cultural, con sentido universal y sentido crítico, con aptitudes para conquistar y practicar sus derechos humanos.

\section{El eje de la corrección de la distribución del ingreso y la riqueza}


La democratización del acceso a la propiedad privada, a las empresas y al mercado es quizás uno de los aspectos más importantes de la estrategia bolivariana en torno a la búsqueda de inclusión. Si bien está desglosado en las LGPDESN en al menos 5 sub-ejes, son dos los que se han venido impulsado con fuerza por parte del gobierno desde 2001, muy especialmente después del paro-sabotaje petrolero de diciembre 2002 - febrero 2003, cuando el Estado logró control sobre PDVSA, su industria estratégica, con lo cual recuperó un recurso de primer orden para acometer el desarrollo del proyecto bolivariano. La política de regularización de tierras rurales y urbanas y el impulso a la "economía social" se han constituido en dos políticas medulares del proceso bolivariano en su meta de superar la exclusión de las mayorías.

\subsection{La Ley de Tierras y el decreto No. 1.666}

La Ley de Tierras y Desarrollo Agrario, aprobada como ya se señaló, mediante ley Habilitante en noviembre de 2001, conjuntamente con el Decreto Presidencial no. 1.666 (aparecido en GO 37.378 referido a la regularización de la tenencia urbana) de febrero de 2002, persiguen la regularización de la tenencia y/o adjudicación de títulos de propiedad tanto en el campo como en la ciudad. Ambas fueron sancionadas antes del golpe de Estado del 11 de abril de 2002, recibiendo un impulso sostenido después de éste y especialmente con posterioridad al paro-sabotaje petrolero. La regularización de la tenencia de tierras rurales a través de la ley de Tierras, ha implicado una tensión muy acentuada entre el gobierno de Chávez y propietarios agrarios, a pesar de que ésta está hecha para adjudicar principalmente tierras que son del Estado $\underline{5}$. Fue el conflicto inicial del gobierno con sectores empresariales que desembocó en el golpe de Estado (López Maya, 2002a). El decreto 1.666, de regularización de tierras urbanas, inició el proceso tendente a regularizar la tenencia de la tierra en los barrios urbanos del país. Se calcula que cerca del $50 \%$ de los venezolanos viven en asentamientos urbanos sin planificación, conocidos en Venezuela como "barrios" (Iglesias, 2002). Este proceso de regularización de la tenencia en los barrios de las ciudades ha estado más rezagado, y aún se espera por la aprobación de una Ley que está en borrador y que se ha prometido hacer aprobar por la Asamblea Nacional para el 2004, luego de un amplio proceso de consulta con los sujetos de la política. Hasta la fecha, ambos procesos han desencadenado una intensa dinámica de organización en el campo y los barrios, toda vez que las normas exigen la constitución de Comités Rurales de Tierras y Comités Urbanos de Tierras (CRT y CUT), con la finalidad de gestar las acciones necesarias para la adjudicación. Tanto los CRT como los CUT gestionan a través de asambleas y otras modalidades de participación organizada el levantamiento de la información sobre población, viviendas, historia y mapas de la 
comunidad, entre los requisitos que deben cumplir para acceder a la propiedad. Ésta puede ser individual o colectiva y existen limitaciones para su venta.

Los primeros datos sobre el avance de estas políticas señalan que entre 2002 y 2003 se adjudicaron entre cartas agrarias y títulos de propiedad en el campo unos 1,5 millones de hectáreas beneficiando a unas 130.000 familias (Wilpert, 2004). Esto viene a ser alrededor de unas 11,5 hectáreas de promedio por familia y una población beneficiaria total de cerca de 650.000 personas (basándonos en una media de cinco miembros por hogar). Por otra parte, para octubre de 2003, cerca de 30.000 títulos de propiedad se otorgaron en ciudades, en Caracas principalmente, registrándose unos 3.000 CUT (Provea, 2003: 223-236). Estos CUT han facilitado también la participación vecinal en otra serie de actividades conexas, como organización para recolección y limpieza en sus comunidades, colaboración en solución de problemas del servicio de agua, atención a los médicos que llegan con el Plan Barrio Adentro, entre otros (Provea, 2003: 223-236).

\subsection{La economía social}

Otro aspecto medular de este eje, que ha recibido un respaldo significativo, en especial, después del paro-sabotaje, son diversas políticas tendientes a impulsar la economía social, entendida como una forma "alternativa" y más democrática, autogestionaria y cogestionaria de actividad productiva y de servicios (Vila, 2003). La Constitución señala que se busca un mayor equilibrio entre la eficiencia económica y la justicia social "dando libertad a la iniciativa privada y preservando el interés colectivo" ( $v$. Constitución, Exposición de motivos). Se consideran parte de esa economía social el sector de las cooperativas, empresas campesinas, microempresas, la pequeña y mediana industria, entre otros. La economía social está respaldada, por una parte, por un sistema de microfinanzas para darle acceso financiero y técnico a quienes se orienten a esta actividad. Se han creado, entre otros, el Banco del Pueblo Soberano, Banco de la Mujer, etc. Por otra parte, también se están desarrollando programas de comercialización para esta producción, como la Misión Mercal, que ha venido creciendo hasta constituirse en una poderosa distribuidora de alimentos. Otro aspecto importante es la capacitación para coempresarios y trabajadores. La economía social tiene en la demanda pública un soporte fundamental para la democratización por el lado del mercado (Vila, 2003). De hecho, desde 2003, una vez logrado el control de PDVSA por parte del Estado nacional, se han venido impulsando las llamadas "ruedas de negocios" donde se saca a licitación las compras tanto de esta empresa como de otros entes públicos (CVG, ministerios, etc.) con miras a incentivar la dinamización del sector de cooperativas, micro empresarios, y de la pequeña y mediana industria. 


\section{El eje de la equidad en el acceso y ejercicio de los derechos humanos}

Este segundo eje de las LGPDESN consiste en un conjunto de políticas sociales tendientes a garantizar el derecho a la identidad, educación, salud, vivienda, deporte, seguridad ciudadana, etc. Tres son a la fecha las líneas que llevan mayor desarrollo y son también medulares en la democracia sustantiva que se busca: las políticas dirigidas a garantizar el derecho a la identidad, a la educación con calidad y a la salud.

\section{1. "Yo soy venezolano, yo soy venezolana"}

La falta de identidad es el primer paso en el camino de la exclusión, siendo que en las últimas décadas este problema venía creciendo en Venezuela. Desde 2000 y bajo la asistencia técnica de la Unicef el gobierno nacional comenzó un Plan Nacional de Identidad (PNI) con el fin de garantizar a toda persona que nace en el territorio nacional su derecho a la identificación y a la nacionalidad. El plan intenta superar algunas de las violaciones a los derechos humanos que la falta de un documento de identidad oficial conlleva: no se existe legalmente, no se puede acceder a servicios básicos, al sistema educativo, al sistema de seguridad social o al estatus familiar (Unicef, 2003).

EI PNI ideó la creación de Unidades Hospitalarias de Registro Civil de Nacimientos (UHRCN), para garantizar que todos los nacidos en hospitales públicos obtengan de una vez su derecho de ser ciudadanos y a tener un nombre (se calcula que el $94 \%$ de los venezolanos nacen allí). Para quienes no tienen actualmente una identificación, o viven en lugares remotos donde resulta difícil acercarse a lugares de registro, en especial para las comunidades indígenas, se concibieron operativos especiales. El gobierno nacional lo llama plan: “yo soy venezolano, yo soy venezolana". La primera UHRCN se creó en el año 2000, en el estado Zulia; posteriormente, la Maternidad Concepción Palacios ubicada en Caracas puso uno en funcionamiento, allí se emiten un promedio de 60 partidas de nacimiento diarias. En el año 2003, la meta fue ampliar las UHRCN a 4 establecimientos del Área Metropolitana de Caracas y llevar el plan a 8 estados del país. Desde 2001 se opera a través de una coordinación entre los ministerios de Interior y Justicia, y Salud y Desarrollo Social, así como apoyos de los centros de salud de gobiernos regionales y de la Alcaldía Mayor de Caracas. El plan incluye también la modernización gradual del Registro Civil de Nacimientos (Unicef, 2003).

\section{2. "Yo sí puedo" y otras políticas en educación}


Desde que se iniciara la gestión del gobierno bolivariano el sector educativo ha sido de modo explícito central al proyecto político que se busca desarrollar, cumpliendo con las funciones de capacitación y formación del ciudadano participativo y responsable. El primer paso se plasmó en la Constitución misma, que ratificó la universalidad del derecho a la educación y la gratuidad de la educación pública en todas sus etapas. El gobierno ha creado desde entonces instrumentos institucionales para preservar esta gratuidad, logrando eliminar el pago de cuotas y bonos de entrada en escuelas públicas, práctica que fue común en años anteriores. El proyecto de las escuelas bolivarianas iniciado en septiembre de 1999 con el objetivo de inducir el regreso de los niños a la educación básica oficial, mediante el atractivo del retorno al horario completo, garantizándoles comidas y merienda, útiles y uniformes, y acondicionando los planteles ha sido una iniciativa importante. Pese a las críticas e ineficiencias que se han detectado en los 5 a ños que lleva funcionando, para julio de 2004, el ministro de Educación y Deportes (MED) informó de la apertura de 3.300 escuelas bolivarianas y la continuación del proyecto para llevarlas a 3.500 a fines de este año (Istúriz en Radio Nacional, 15-07-04)‥ Este esfuerzo, acompañado de un significativo aumento del gasto público en educación a todos los niveles, ha resultado en un aumento sostenido de la matrícula escolar desde el período 1999-2000 (Provea, 2003: 189).

Una vez superadas el golpe de Estado del 11 de abril y el paro-sabotaje petrolero de diciembre 2002-febrero 2003, el gobierno acometió con mayor fuerza y más claridad objetivos de inclusión a través de la educación. En julio de 2003 comenzó la llamada “Misión Robinsón”, un plan de alfabetización masivo implementado por una acción cívicomilitar conjunta. Este plan, a través de 65 sesiones de dos horas cada una, prepara al participante en las destrezas básicas del leer y escribir. El método, conocido como "yo sí puedo", se apoya en un facilitador, en muchos casos jóvenes de las mismas comunidades o maestros y maestras jubiladas, a quien se le da una preparación previa. Se utilizan como materiales una cartilla y material audiovisual (Misión Robinson, 2003). En el censo de 2001 se calculó el número de analfabetas en Venezuela en 1,154.120. Para diciembre de 2003 las cifras oficiales de captación de "patriotas" (así se llamaron a quienes se censaron para la misión) alcanzaban el 1,252.226, de los cuales 1,203.314 recibieron o estaban recibiendo clases (Misión Robinson, 2003). La misión Robinsón abrió posteriormente una fase II, mediante la cual se facilita a los alfabetizados obtener su diploma de sexto grado en un período de dos años. Si se toma en cuenta que el $52 \%$ de los analfabetas registrados tienen menos de 30 años, se puede sopesar la significación definitiva que esta misión tiene para mejorar las expectativas de futuro de más de medio millón de venezolanos. 
También en 2003 el gobierno impulsó la misión Ribas y la misión Sucre. Con la misión Ribas, se busca que los venezolanos que no pudieron terminar su bachillerato pueden ahora hacerlo. Según las cifras gubernamentales, de los alrededor de 5 millones que abandonaron sus estudios secundarios, más de 1,350.000, en su inmensa mayoría jóvenes, acudieron al llamado a censarse en noviembre de ese año (CIED, 2003)ㄱ. De éstos comenzaron a recibir clases unas 273.000 personas a mediados de ese mes, y el gobierno otorgó unas 75.141 becas hasta el 17-12-03 a "los más necesitados, desempleados, madres solteras quienes tendrán prioridad para que mejoren sus condiciones de vida" (Chávez en CIED, 2003). La misión Ribas está siendo coordinada nacionalmente por el Ministerio de Energía y Minas, y apoyada por el Ministerio de Economía, Cultura y Deportes, la industria petrolera (PDVSA), y el Centro Internacional de Educación y Desarrollo (CIED), una filial de PDVSA.

La misión Sucre, por su parte, busca subsanar el problema de los bachilleres pobres y de clases medias que no encuentran cupo en las universidades del país. Forma parte de un plan más general, coordinado por el Ministerio de Educación Superior -ente creado por el gobierno de Chávez dentro de su enfoque de relevar la Educación en sus distintos nivelespara remediar el problema de la falta de acceso de los pobres a este nivel. Desde 1999 el gobierno nacional ha creado 5 universidades y 4 institutos universitarios tecnológicos, la mayoría de ellos en el interior del país. También implementó el proyecto Alma Mater que incluye un plan de becas para estudiantes muy pobres que aprueban la Prueba de Aptitud Académica (Fuenmayor, 2003). En el último cuatrimestre de 2003 se inauguró la Universidad Bolivariana de Venezuela con una matrícula de 2.000 estudiantes (Fuenmayor tomado de Radio Nacional en internet, 2004). Se hizo entonces un primer censo de estudiantes que se encuentran excluidos del sistema superior. La misión Sucre comenzó poco después, en noviembre de 2003, según cifras del gobierno, con 60.000 seleccionados, algunos de los cuales esperaban cupo desde antes de 1990. Al igual que con la misión Ribas, se otorgaron becas a los más necesitados ( $v$. www.embavenezparis.com, 2004). Para julio de 2004 la Universidad Bolivariana contaba con una matrícula de 9.400 estudiantes distribuidos en tres sedes: Caracas, Maracaibo (estado Zulia) y Ciudad Bolívar (estado Bolívar) y esperaba llevar a 27.000 estudiantes la matrícula del período académico 2004-2005, incorporando a estudiantes de la misión Sucre (Castellanos en Radio Nacional en internet, 2004).

\subsection{Misión Barrio Adentro}

Otra estrategia medular para atacar la exclusión social desde el aspecto del derecho a la salud es el Ilamado primeramente Plan Barrio Adentro, convertida en 2004 en Misión 
Barrio Adentro. Surgió después de las insurrecciones de la oposición, como una iniciativa del Presidente para promover el desarrollo de la salud, educación, cultura y deporte en las comunidades más necesitadas del país, aquéllas que por lo demás, demostraron un compromiso de apoyo activo y sostenido al gobierno de Chávez durante la crisis política. Esta misión está fundamentalmente centrada en ofrecer a los barrios urbanos servicios de salud in situ, que incluyen: atención médica gratuita, suministro gratuito de medicinas, atención domiciliaria y servicio las 24 horas del día (Barrio Adentro, 2003). Mediante un convenio internacional entre la República de Cuba y Venezuela, profesionales de la medicina cubanos conjuntamente con médicos venezolanos comenzaron en abril de 2003 a brindar asistencia médica a los municipios Libertador y Sucre del área metropolitana de Caracas y de all í se fue expandiendo espacialmente hasta cubrir en 2004 todos los estados y municipios del país. El componente médico venezolano fue inicialmente mínimo, ya que las condiciones en las cuales se trabaja en los barrios urbanos no es atractivo para estos profesionales y la Federación Venezolana de Médicos le hizo una feroz oposición. Sin embargo, en 2004 se fueron incorporando médicos y enfermeras venezolanas y bajó la resistencia del gremio médico, dadas las bondades de la misión y su positivo impacto político.

Según datos oficiales de fines de 2003 (Aló Presidente, 2003), para diciembre habían llegado al país unos 10.000 médicos cubanos que están dispersos en los distintos barrios urbanos de las ciudades venezolanas. Según la jefa de la misión médica cubana, cada médico recibe unas 16 consultas diarias en las mañanas y hacen unas 9 visitas a las casas en las tardes. A fines de 2003 el programa pasó a llamarse "Misión Barrio Adentro" con la inauguración de los primeros núcleos o "módulos" de atención médica primaria, y la creación de centros de apoyo y servicios oftalmológicos y odontológicos. Los módulos, que cuentan para su construcción con la colaboración de las comunidades donde el médico presta su servicio, tienen una forma hexagonal característica y constan de dos plantas, la de abajo es para la consulta y la de arriba sirve como vivienda del médico. Mientras se construyen los módulos el médico u odontólogo es alojado en viviendas o cuartos acondicionados por los mismos vecinos.

Como lo han señalado muchos testimonios, independiente de sus muchas fallas e improvisaciones, es la primera vez que un gobierno lleva a los barrios una política de salud masiva para la población necesitada. Se calculaba para octubre de 2003, que el plan había logrado salvar más de 700 vidas (www. barriooadentro.gov.ve, 2003), sin contar las numerosas emergencias que fueron solucionadas sin que hubiese que dirigirse a los deficientes y/o colapsados puestos ambulatorios y hospitales. Hacia mediados de 2004, el Presidente informó en su programa semanal "Aló Presidente", transmitido desde el sector 
popular de los Jardines del Valle en Caracas, que esta misión había roto todas las expectativas al haber alcanzado para esa fecha la cifra de 45 millones 641 mil casos atendidos ${ }^{-}$. Ofreció la apertura de 150 módulos en la gran Caracas antes de finalizar el año (aló presidente $N^{\circ} 196,2004$ ).

\section{El eje del empoderamiento}

El tercer eje del equilibrio social busca "dar el salto hacia la materialización de una democracia participativa y protagónica" creando una nueva relación entre sociedad y Estado, donde lo público sea un accionar corresponsable entre estos dos agentes (LGPDESN, 2001).

Para el proyecto bolivariano, se trata de gobernar con los ciudadanos para lo cual se abren mecanismos de democracia directa en ámbitos económicos, sociales y políticos a los fines de dejar fluir por ellos la participación ciudadana en todas las etapas de formación, diseño, ejercicio y control de la gestión pública a todos los niveles político-administrativos. La Constitución de 1999 en su artículo 62 ya enunciado, afirma que la condición participativa de los ciudadanos es imprescindible para alcanzar su desarrollo integral en el camino hacia una profundización de la democracia.

En la Constitución se aprobaron varios instrumentos de participación directa en lo político, como son los distintos referendos (aprobatorio, consultivo, revocatorio), la iniciativa legislativa, constitucional y constituyente, el cabildo abierto y las asambleas de ciudadanos (v. artículo 70). Con ellos se persigue propiciar la injerencia directa de los ciudadanos en las decisiones del Estado y someter a los electos al mandato popular revocatorio (Álvarez, 2003: 197). Así mismo se estableció en lo social y económico el reconocimiento constitucional a instancias de atención ciudadana, cogestión, autogestión, cooperativas, cajas de ahorro, empresas comunitarias y toda forma asociativa guiada por valores de mutua cooperación y solidaridad (artículo 70).

En medio de las vicisitudes de la alta conflictividad y polarización sociopolítica que han caracterizado a la sociedad venezolana durante estos años de gobierno del presidente Chávez, ha venido avanzando de manera irregular esta democracia participativa tanto en su construcción institucional como en las prácticas sociales de los sectores populares y de clases medias. La Ley de Consejos Locales de Planificación Pública, aprobada en junio (Gaceta Oficial N³7.463, 2002), materializó y reguló un instrumento que hace obligatoria la gestión conjunta de la sociedad organizada localmente con la gestión pública a ese nivel, incentivando la dinámica normativa y asociativa que ésta ley promueve 
(Provea, 2002-2003: 474-475). También ha tomado importante impulso las llamadas "mesas técnicas de agua" y los "consejos comunitarios de agua", mediante los cuales las empresas públicas hidrológicas promueven procesos organizativos en las comunidades a los fines de que éstos asumen la gestión de estas empresas públicas (Lander, 2004). Por otra parte, las cooperativas de diversa naturaleza han crecido potencialmente, al calor de los estímulos que han recibido por las iniciativas estatales como el acceso a micro créditos dentro del sistema de micro finanzas establecido por el gobierno. Y también por la política de compras gubernamentales a través de "ruedas de negocios", donde entes y empresas públicas como PDVSA, la CVG, y los ministerios e institutos autónomos, sacan a licitación sus listas de compras dando preferencia a cooperativas y pequeñas y medianas industrias nacionales (Provea, 2002-2003: 475)9. I gualmente, estimulado por la posibilidad inédita de alcanzar la propiedad de sus tierras rurales o urbanas, como ya se señaló, se ha venido fortaleciendo entre los sectores populares, un proceso de organización de CUT y CRT que han servido para adelantar actividades comunitarias más allá de lo que es su propósito inicial $\underline{10}$.

\section{Conclusión}

En Venezuela avanza un proyecto político de democracia participativa, que constituye una novedosa y creativa respuesta de actores políticos emergentes de izquierda a las condiciones socioeconómicas y políticas que atravesó esta sociedad en los años 80 y 90 . A diferencia de muchos países latinoamericanos, en Venezuela no se produjo un colapso de la democracia representativa con el agotamiento del modelo de sustitución de importaciones. Al contrario, se vivió una degradación de esa democracia que condicionó la manera con que los venezolanos se aproximaron al debate y las prácticas democráticas de fines de siglo. Los actores de vocación popular o de izquierda que emergen desde fines de los años 80 en una sociedad que rechaza crecientemente su viejo régimen político, van esbozando y ofreciendo al electorado un proyecto de democracia profunda y de desarrollo económico nacionalista, de rechazo a la globalización económica neoliberal. En 1999, con el triunfo electoral de Hugo Chávez Frías y su alianza de fuerzas sociales y políticas conocida como el Polo Patriótico, comienza a materializarse este proyecto alternativo. La aprobación de la Constitución de 1999 y de las Ĺneas Generales del Plan Económico y Social, 2001-2007, son las primeras bases institucionales, a partir de las cuales se ha venido levantando el edificio de la "V República".

En los textos oficiales, la concepción de la llamada "democracia participativa y protagónica" refleja una asimilación de ideas del debate teórico sobre democracia, que se dio en la región en las últimas décadas del siglo. Se materializa en éstos un enfoque de 
democracia sustantiva a profunda, a diferencia de la procedimental, que se generalizó en los países del cono sur, que experimentaron dictaduras en las décadas previas. Claramente se busca un tipo de régimen donde se promueva el autodesarrollo de los ciudadanos y su autogestión para resolver conjuntamente con el Estado los graves problemas de exclusión e injusticia social que padecen las mayorías. En el camino hacia la equidad, la inclusión, la prosperidad y la democracia plena, se parte de una visión holística ante los problemas -se diagnostican éstos como "estructurales"- y se conciben 5 equilibrios interrelacionados que deben establecerse en la sociedad. El equilibrio social, busca corregir la exclusión y la injusticia social, potenciando al mismo tiempo el desarrollo de un ciudadano capacitado para la solidaridad y el ejercicio pleno y activo de sus derechos democráticos.

Resulta aún difícil evaluar este proyecto en sus realizaciones concretas, toda vez que las pautas y cifras sobre distintas políticas y misiones sociales que se manejan son todas oficiales. No obstante, en estos 5 años, con especial énfasis después del paro-sabotaje petrolero de 2002-2003, como se ha reiterado en esta exploración, se han ido concretando varios aspectos centrales de los subejes propuestos por las LGPDESN. Hemos señalado la relevancia de la inicial aplicación de la Ley de Tierras y Desarrollo Agrario, así como del decreto 1.666 de regularización de las tierras urbanas, por la dinámica organizativa que ellas vienen estimulando entre los sectores populares del campo y de la ciudad como instrumentos de autodesarrollo y autogestión de sus problemas con miras a superarlos. En esa misma dirección, el impulso a la economía social ha venido avanzando a través del estímulo a las cooperativas y gracias a las ruedas de negocio, a la creación de un sistema de microfinanzas, y otras actividades que crean un ambiente propicio a la creación de empleos y al crecimiento y fortaleza de una red de pequeños y medianos empresarios en el país. En el subeje concebido para articular estrategias sociales que permitan el acceso a derechos como la educación, la salud, la vivienda, entre otros, destacan las políticas educativas y de salud, que más allá de las críticas y dudas que se tienen sobre su eficiencia y viabilidad material, han venido a saldar una deuda social con la población pobre que este Estado petrolero dejó llegar a niveles intolerables para cualquier democracia. En lo relativo a la creación de canales institucionales para la apertura de la participación protagónica de las comunidades y ciudadanos, se señalan los referendos constitucionales, ya puestos en práctica recientemente con el referendo presidencial del 15 de agosto de 2004, así como, en el ámbito social, la aprobación de la Ley de los Consejos Locales de Planificación Pública y otros diversos instrumentos de organización y participación organizada de los ciudadanos.

El proyecto así esbozado dista mucho de ser un producto acabado y coherente. Muchas 
inconsistencias y contradicciones aún persisten en ella. Sin embargo, se ha ido mejorando y ampliando, tomando formas más precisas en la medida en que las luchas populares por defenderla han abierto los espacios de la creatividad popular. Es la medida en que diversos sectores sociales se apropien de este proyecto y de los instrumentos que se han ido sancionando institucionalmente, se podrá ir avanzando en la solución democrática de los problemas, y podrá erigirse en orientador de un modelo alternativo de democracia sustantiva para los sectores populares latinoamericanos.

\section{Notas}

1. Hay una literatura abundante sobre la materia. Un resumen con aspectos resaltantes del debate puede verse entre otros en Lander (1995) y Ellner (2002).

2. Sobre partidos políticos de izquierda en la Venezuela de fines de siglo, puede verse López Maya (2002b).

3. Sobre conductas torpes y autoritarias del gobierno de Chávez con anterioridad al golpe de Estado puede verse Parker (2002). Sobre la ilegalidad del procedimiento para elegir a los miembros del TSJ véase Provea (1999-2000 y 2000-2001, capítulo “Derecho a la justicia”). También Álvarez, 2003: 194-195).

4. Sobre la etapa insurreccional de la oposición al gobierno de Chávez, véase López Maya (2004).

5. En Venezuela el Estado es un gran latifundista por haberle expropiado las propiedades al general Gómez, dictador entre 1907 y 1935. Debido a su condición petrolera, mucha de la tierra pública ha sido apropiada por privados en el desarrollo del siglo XX. Éstos se sienten dueños de esas tierras a pesar de no contar con títulos de propiedad. Ello explica parcialmente la poderosa resistencia que esta ley ha suscitado entre grandes propietarios.

6. Para una evaluación crítica de las escuelas bolivarianas ver Provea, informes anuales desde 2000. Unas primeras declaraciones de Istúriz se produjeron en el barrio popular de La Vega y fueron trasmitidas en el Aló Presidente no. 175 realizado en Maracaibo en diciembre de 2003 (ver www.rnve.orq.ve bajado el 22-12-03). En 2004 el Ministerio de Educación, Cultura y Deporte (MECD) pasó a llamarse Ministerio de Educación y Deporte, al crearse un Ministerio de Cultura.

7. Agradezco a las profesoras Marian Hanson y Haydée Nava del CIED haberme proporcionado estos datos. Me han advertido que aun son provisionales y pueden contener algunas imprecisiones.

8. En junio, Fernando Bianco, presidente del Colegio de Médicos del Dto. Federal, calculó que se está cubriendo una población de cerca de 12 millones (del total de 23 millones que tiene el país), (en www.rnv.org.ve bajado el 17-07-04).

9. De acuerdo con la Superintendencia Nacional de Cooperativas en 2001 había 1.948 cooperativas. Para julio de 
2003 estaban registradas 10.032 .

10. En los informes anuales de Provea se dedica un capítulo "Respuestas organizativas de la sociedad" a la dinámica organizativa que se viene produciendo en distintos espacios de la sociedad. Allí puede seguirse con más detalle la evolución de la democracia participativa en estos años de gobierno.

\section{Referencias Bibliográficas}

1. Álvarez, Ángel (2003), "La reforma del Estado antes y después de Chávez" en Steve Ellner y Daniel Hellinger, eds., La política venezolana en la época de Chávez. Clases, polarización y conflicto, Caracas, Nueva Sociedad.

2. Centro Internacional de Educación y Desarrollo (CIED) (v. www.rnv.org.ve (2003), Cita de Chávez en la sesión de apertura de las clases. Fecha de Consulta: 22-12-03

3. Ellner, Steve (2002), "Literatura reciente sobre la democracia latinoamericana", Revista Venezolana de Economía y Ciencias Sociales, vol. 8, no. 1, pp.133-152.

4. Fuenmayor, Luis (2003), “Excelencia académica y equidad en el sector superior educativo", Revista Venezolana de Economía y Ciencias Sociales, vol. 9, no. 1, pp. 229232.

5. Gaceta Oficial (2003), N³7.463. Imprenta Nacional. Venezuela.

6. Iglesias, María Cristina (2002), “I deas para la democratización del territorio" (papel de trabajo $N^{\circ} 1$ ), IV Asamblea Nacional del PPT, San Juan de los Morros.

7. Lander, Edgardo (1995), Neoliberalismo, sociedad civil y democracia. Ensayos sobre América Latina y Venezuela, Caracas, Ediciones de la UCV.

8. Lander, Edgardo (2004), "Venezuela, la búsqueda de un proyecto contrahegemónico", Question (Caracas), Año 3, no. 25, pp. 20-24.

9. Lechner, Norbert (1994), “Los nuevos perfiles de la política: un bosquejo", Nueva Sociedad, no 130, marzo-abril, pp. 32-43.

10. Lgpdesn (2001), “Líneas Generales del Plan de Desarrollo Económico y Social de la Nación, 2001-2007", Caracas, bajado de Internet, 06-09-2004. 
11. López Maya, Margarita (2002a), "El golpe de Estado del 11 de abril y sus causas", Sociedad y Economía (Cali), no. 3, pp. 7-18.

12. López Maya, Margarita (2002b), "partidos de izquierda en Venezuela al comenzar el siglo XXI: El Movimiento Quinta República y el Patria Para Todos", trabajo presentado en el Grupo de Trabajo Partidos Políticos de Clacso, Campinas, noviembre, inédito.

13. López Maya, Margarita (2004), Venezuela 2001-2004: actores y estrategias en la lucha hegemónica, trabajo presentado en el Grupo de Trabajo Historia Reciente de Clacso, Montevideo, agosto, inédito.

14. López Maya, Margarita y Luis E. Lander (2000), “Ajustes, costos sociales y la agenda de los pobres en Venezuela: 1984-1998", Revista Venezolana de Economía Ciencias Sociales, vol. 6, no. 3, pp. 185-208.

15. Novarro, Marco (1997), "El liberalismo político y la cultura política popular", Nueva Sociedad, no. 149, pp. 114-129. Caracas.

16. Manin, Bernard (1992), “Metamorfosis de la representación" en Mario Dos Santos (coord.), ¿Qué queda de la representación política?, Caracas, Editorial Nueva Sociedad.

17. Misión Barrio Adentro (www. barrioadentro.gov.ve, 2003). Fecha de Consulta: 14-1203.

18. Misión Ribas (www.embavenez-paris.com, 2004). Se otorgaron becas a los más necesitados. Fecha de Consulta: 02-01-04.

19. Misión Robinson, ( www.misionrobinson.gov.ve). Fecha de consulta: 04-12-03

20. Parker, Dick (2002), “Debilidades en la conducción política también facilitaron el golpe", Observatorio Social de América Latina, no. 7, junio, pp. 11-14.

21. Provea (1999-2000 en adelante), Situación de los derechos humanos en Venezuela. Informe anual octubre 1999-septiembre 2000 en adelante, Provea, Caracas.

22. Roberts, Kenneth (1998), Deepening Democracy? The Modern Left and Social Movements in Chile and Peru, Stanford, Stanford University Press. 
23. Roberts, Kenneth (2003), “Polarización social y resurgimiento del populismo en Venezuela" en Steve Ellner y Daniel Hellinger, La política venezolana en la época de Chávez. Nueva Sociedad, pp. 75-96. Caracas.

24. Vergara, Jorge (1998), “Teorías democráticas participativas", Revista Venezolana de Economía Ciencias Sociales, no. 2-3, pp. 155-179.

25. Vila, Enrique (2003), “La política social del proyecto bolivariano: ideas controversiales", Revista Venezolana de Economía Ciencias Sociales, no. 3, pp. 111-144.

26. Wilpert, Gregory (2004), "Venezuela. La lucha contra la pobreza”, tomado de www.vwnwzuelanalysis.com, bajado el 5-1-2004.

\section{Entrevistas}

27. Aristóbulo Istúriz, dirigente del PPT. Miembro del Equipo Político, actual ministro de Educación y Deportes, entrevista realizada el 20 de agosto de 1997 en las oficinas del PPT en Los Caobos, Caracas.

28. Núñez Tenorio, José Rafael, dirigente e ideólogo del MVR. Entrevista realizada el 18 de agosto de 1997 en su oficina en la Ave. Negrín, Caracas. 